\title{
Hipertiroidi Hastalarında Tedavi Öncesi ve Sonrası Trombosit/Lenfosit ve Nötrofil/Lenfosit Oranlarının Değerlendirilmesi
}

\section{The Evaluation of Pretreatment and Posttreatment Platelet/Lymphocyte and Neutrophil/Lymphocyte Ratios in Patients with Hyperthyroidism Ciğdem CiNDOĞLU ${ }^{1} \mathbb{D}^{(D)}$, Mehmet Sidar GÜLER ${ }^{1}$ (D), Mehmet Ali EREN 2 (D), Tevfik SABUNCU 2}

\author{
1 Harran Üniversitesi Tıp Fakültesi Hastanesi İç Hastalıkları Anabilim Dalı, Şanlıurfa \\ 2 Harran Üniversitesi Tıp Fakültesi Hastanesi İç Hastalıkları Anabilim Dalı, Endokrinoloji Bilim Dalı, Şanlıurfa
}

Öz.

Amaç: Hipertiroidizm, yüksek serbest triiyodotironin (serbest T3) ve / veya serbest tiroksin düzeyleri (serbest T4) ile birlikte subnormal (genellikle saptanamayan) bir serum tirotropin (TSH) olarak tanımlanır. Endojen hipertiroidi en sık Graves hastalı̆ı $(\mathrm{GH})$ veya nodüler tiroid hastalı̆ına bağlıdır. GH bașta tiroid bezi olmak üzere, göz ve nadiren cildi tutan otoimmün bir hastalıktır. Hastalık genelde hipertiroidiye bağı semptomlar ile tanınır. Tedavisinde anti-tiroid ilaçlar kullanılmakta olup, bu ilaçlar tiroid hormon sentezinin yanı sıra anti-inflamatuar özelliklere de sahiptir. Trombosit/lenfosit (TLO) ve nötrofil/lenfosit (NLO) oranları ise rutin kan sayımından elde edilen, ucuz ve tekrarlanabilir, sistemik inflamasyon belirteçleridir. Hipertirodide tedavi öncesi ve tedavi sonrası TLO ve NLO' nın değerlendirilmesi amaçlanmıştır.

Materyal ve Metod: Çalışmaya Harran Üniversitesi Tıp Fakültesi Endokrinoloji Polikliniği'ne başvuran hastaların geçmișe yönelik kayıtları incelenerek hipertiroidi tanısı alan ve medikal tedavi başlanan hastalar alındı. Aktif enfeksiyonu ve hematolojik patolojisi olan hastalar çalışmaya dahil edilmedi. Hastaların kayıtlarından tanı anındaki ve 3-6 ay sonraki laboratuvar sonuçları değerlendirildi. Medikal tedavi öncesi ve sonrası NLO ve TLO değerlerinin karşılaştıııması planlandı.

Bulgular: GH grubunda tedavi öncesi ve tedavi sonrası TSH, sT3, sT4, lökosit, nötrofil, lenfosit ve hemoglobin düzeylerinde artış vardı ve bu artış istatistiksel anlamlıydı. Bununla birlikte toksik nodüler guatr (TNG)/multınodüler guatr (MNG) grubunda TSH, sT3, sT4 değerlerinde anlamlı artış varken, lökosit, nötrofil, lenfosit ve hemoglobin düzeylerinde tedavi öncesi ve sonrası anlamlı bir fark yoktu. GH grubunda NLO tedavi sonrası öncesine göre anlamlı yüksekti ancak TLO'nda anlamlı fark gözlenmedi Sonuç: Hipertiroidi özellikle en sık nedeni olan GH hemotolojik parametrelerde çeşitli mekanizmalarla değişiklik yapabilmektedir. Antitiroid ilaçlar tiroid hormon düzeyleriyle birlikte kan sayımında da değişikliklere neden olur

Anahtar Kelimeler: Graves hastalığı, Nötrofil/lenfosit oranı, Trombosit/lenfosit oranı

Abstract

Background: Hyperthyroidism is defined as subnormal (usually undetectable) serum thyrotropin (TSH) with elevated serum levels of free triiodothyronine (free T3) and / or free thyroxine (free T4). Endogenous hyperthyroidism is most commonly due to Graves' disease (GD) or nodular thyroid disease. GD is an autoimmune disease that involves mostly the thyroid gland, the eyes and rarely the skin. The disease is generally recognized by symptoms related to hyperthyroidism. Anti-thyroid medications are used in its treatment, and these medications have anti-inflammatory features besides thyroid hormone synthesis. Thrombocyte/lymphocyte (TLR) and neutrophil/lymphocyte (NLR) rates are systemic inflammatory markers that are obtained from routine blood count, inexpensive and repeatable. It is aimed to evaluate the rates of TLR and NLR before and after treatment in hyperthyroidism.

Materials and Methods: The retrospective records of the patients who were admitted to Harran University Medical Faculty Endocrinology Polyclinic were examined, and patients who were diagnosed with hyperthyroidism and started medical treatment were included in the study. Patients with active infection and hemorrhagic pathology were excluded from the study. Laboratory results of the patients at the time of diagnosis and results after 3-6 months were evaluated. It was planned to compare NLR and TLR values before and after medical treatment.

Results: In the GD group, there was an increase in TSH, fT3, fT4 leukocyte, neutrophil, lymphocyte and hemoglobin levels before and after treatment, and this increase was statistically significant. Nevertheless, there was a significant increase in TSH, $\mathrm{fT} 3$, fT4 values in the toxic nodular goiter (TNG)/ multinodular goiter (MNG) group, while there was no significant difference in leukocyte, neutrophil, lymphocyte and hemoglobin levels before and after treatment. In the GD group, NLR of after treatment was significantly higher than before, but no significant difference was observed in the TLR.

Conclusions: GD, which is the most common cause of hyperthyroidism, can change hematological parameters with various mechanisms. Antithyroid medications cause changes in blood count along with thyroid hormone levels.

Key words: Graves' disease, Thrombocytellymphocyte rates, Neutrophil/lymphocyte rates

\section{Sorumlu Yazar I \\ Corresponding Author}

\section{Dr. Çiğdem CINDOĞLU \\ Harran Üniversitesi Tıp Fakültesi, İç \\ Hastalıkları Anabilim Dalı \\ Osmanbey Kampüsü Şanlıurfa}

Tlf: 05052281375

e- mail: ccindoglu@gmail.com

\section{Geliş tarihi / Received:}

04.03.2020

Kabul tarihi / Accepted: 11.03 .2020

DOI: $10.35440 /$ hutfd.698311 


\section{Giriş}

Hipertiroidizm, yüksek serbest triiyodotironin (sT3) ve/veya serbest tiroksin (sT4) düzeyleri ile subnormal (genellikle saptanamayan) serum tirotropin/tiroid stimülan hormon (TSH) düzeyi olarak tanımlanır ve artmış tiroid hormon sentezi, önceden sentezlenmiş tiroid hormonlarının aşırı salınması veya endojen/ekzojen ekstratiroidal bir kaynağın neden olduğu dokulardaki aşırı tiroid hormon konsantrasyonuna bağlı gelişir. Hipertiroidinin en yaygın nedenleri Graves hastalı̆ıı(GH)(en sık), toksik multinodüler guatr ve toksik adenomdur. Tirotoksikozun diğer önemli nedenleri arasında tiroidit, iyodine bağlı ve ilaca bağlı tiroid fonksiyon bozukluğu ve fazla miktarda tiroid hormonunun kullanımı yer alır. Popülasyonun \% 0.5-1.0' ını etkileyen $\mathrm{GH}$, öncelikle tiroid bezi olmak üzere birçok organı da etkilemektedir. GH 'da patolojik mekanizma tam olarak aydınlatılımıs değildir. Genetik, endojen ve çevresel faktörler arasındaki etkileşimler ve immün sistem bozukluğu ile ilişkilendirilmiştir(14). GH, TSH reseptör antikorunun tiroid bezini uyardığı ve hipertiroidizme neden olduğu otoimmün bir hastalıktır. Bu nedenle, konakçı immün sistemi GH' nın baskılanması ve ilerlemesinde önemli bir rol oynar. GH için anti-tiroid ilaçlar, radyoaktif iyot ve tiroidektomi olmak üzere üç tedavi yöntemi vardır ve primer tedavi seçimi bölgesel tercihlere dayanmaktadır(4). Nötrofil lenfosit oranı (NLO) sistemik inflamasyon seviyesini değerlendirmek için yeni ve güvenilir; aynı zamanda ucuz ve kullanışlı bir biyobelirteçtir. Sistemik inflamasyon, tiroid karsinomu, gastrik karsinom ve kolorektal karsinom gibi birçok kanserde önemli bir rol oynar(6-9). Trombosit lenfosit oranı (TLO), trombositlerin mutlak sayımının, rutin tam kan sayımından türetilen mutlak lenfosit sayısına bölünmesidir. TLO, inflamasyonun bir belirteci olarak ortaya çıkmış ve birçok hastalıkta inflamasyonun şiddetini belirlemek için diğer enflamatuar belirteçlerle kombinasyon halinde kullanılmıştır. TLO' nın faydaları, kanserler, kardiyovasküler hastalıklar, romatizmal hastalıklar dahil birçok çalışmada değerlendirilmiştir(10-11).

Son yıllarda NLO ve TLO' nın sistemik inflamasyonun bir göstergesi olabileceği ve birçok kardiyovasküler hastalık, maligniteler ve kronik inflamatuvar hastalıklarda prognoz ile ilişkili olduğu gösterilmiştir. Aynı zamanda NLO ve TLO' nın eritrosit sedimentasyon hızı (ESH), C-reaktif protein (CRP), interlökin-6 (IL-6) ve tümör nekrozis faktör-alfa (TNF-alfa) değerleriyle ilişki gösterdiği tespit edilmiştir(1417). Hipertiroidide; NLO ve TLO' nı birlikte değerlendiren çalışma bulunmamaktadır. Çalışmamızda hipertiroidide tedavi öncesi ve tedavi sonrası NLO ve TLO' nın karşılaştırılması planlandı.

\section{Materyal ve Metod}

Çalışmaya Harran Üniversitesi Tıp Fakültesi Endokrinoloji Polikliniği'ne başvuran hastaların geçmişe yönelik kayıtları incelenerek hipertiroidi tanısı alan ve medikal tedavi başla- nan hastalar alındı. Aktif enfeksiyonu ve hemorajik patolojisi olan hastalar çalışmaya dahil edilmedi. Hastaların kayıtlarından tanı anındaki ve 3-6 ay sonraki laboratuvar sonuçları değerlendirildi. NLO, mutlak nötrofil sayısının lenfosit sayısına bölünmesiyle; TLO, trombosit sayısnın lenfosit sayısına bölünmesiyle hesaplandı. Medikal tedavi öncesi ve sonrası NLO ve TLO değerlerinin karşılaştırılması planlandı. Sonuç olarak çalışmaya $103 \mathrm{GH}$ tanıı, 22 TNG/MNG tanilı toplam 125 hasta dahil edildi. Hipertiroidi olması ve antitiroid ilaç kullanımı bağımsız değişken, TLO ve NLO bağımlı değişken olarak değerlendirildi. Gruplar arası değişkenler Mann-Whitney $U$ testi, grup içinde ise Wilcoxon testi ile analiz edildi. Analizler SPSS 20 istatistik paket programı kullanılarak yapılmıştır. $\mathrm{P}<0.05$ anlamlı olarak kabul edilmiştir. Çalışma protokolü için Harran Üniversitesi Tıp Fakültesi Etik Kurulu tarafından (05.11.2018 tarih, 11 nolu oturum ve 14 nolu karar) onay alınmıştır. Çaış̧ma için kurum izni alınmıştır.

\section{Bulgular}

Çalışmaya 90(\%72)'i kadın, 35(\%28)'i erkek olmak üzere 125 hasta dahil edildi. Bu hastaların $103(\% 74,1)$ 'ü $\mathrm{GH}$, 22(\%25,9)'s। TNG/MNG nedeniyle medikal tedavi verilen hastalardı. Hastaların yaş ortalaması $35.79 \pm 12,07$ (18-77) iken $\mathrm{GH}$ grubunda yaş ortalaması $35.10 \pm 10.96$ (18-73), TNG/MNG grubunda $38,45 \pm 16,10$ (20-77) idi.

Tablo 1. Tedavi öncesi ve sonrası biyokimyasal ve hematolojik parametreler

\begin{tabular}{|c|c|c|c|c|c|c|}
\hline & \multicolumn{3}{|c|}{ Graves Hastalığı } & \multicolumn{3}{|c|}{ Nodüler / Multinodüler } \\
\hline & $\begin{array}{l}\text { Tedavi } \\
\text { Öncesi }\end{array}$ & $\begin{array}{l}\text { Tedavi } \\
\text { Sonrası }\end{array}$ & $P$ & $\begin{array}{l}\text { Tedavi } \\
\text { Öncesi }\end{array}$ & $\begin{array}{l}\text { Tedavi } \\
\text { Sonrası }\end{array}$ & $P$ \\
\hline \multicolumn{7}{|c|}{ Metabolik ve hormonal parametreler } \\
\hline $\begin{array}{l}\mathrm{TSH}, \\
\mathrm{mIU} / \mathrm{L}\end{array}$ & $0.00 \pm 0.33$ & $1.02 \pm 1.50$ & 0.001 & $0.01 \pm 0.53$ & $0.62 \pm 1.07$ & 0.00 \\
\hline $\begin{array}{l}\mathrm{sT3} \\
\mathrm{pg} / \mathrm{mL}\end{array}$ & $9.69 \pm 4.61$ & $3.27 \pm 0.47$ & 0.001 & $6.61 \pm 1.82$ & $2.92 \pm 0.97$ & 0.00 \\
\hline $\begin{array}{l}\mathrm{sT} 4, \\
\mathrm{ng} / \mathrm{dL}\end{array}$ & $2.79 \pm 1.28$ & $1.12 \pm 0.23$ & 0.001 & $2.01 \pm 0.56$ & $1.12 \pm 0.22$ & 0.00 \\
\hline $\begin{array}{l}\text { Glukoz, } \\
\mathrm{mg} / \mathrm{dL}\end{array}$ & $100.21 \pm 25.06$ & $94.29 \pm 16.66$ & 0.005 & $95.31 \pm 15.46$ & $91.40 \pm 19.35$ & 0.28 \\
\hline \multicolumn{7}{|c|}{ Hematolojik parametreler } \\
\hline $\begin{array}{l}\text { Lökosit,/ } \\
\text { mm }^{3}\end{array}$ & $7.79 \pm 1.87$ & $8.51 \pm 1.70$ & 0.000 & $8.70 \pm 2.26$ & $8.93 \pm 1.94$ & 0.636 \\
\hline $\begin{array}{l}\text { Nötrofil, } \\
/ \mathrm{mm}^{3}\end{array}$ & $4.36 \pm 1.75$ & $5.01 \pm 1.72$ & 0.004 & $5.56 \pm 2.08$ & $5.56 \pm 1.86$ & 0.356 \\
\hline $\begin{array}{l}\text { Lenfosit, } \\
/ \mathrm{mm}^{3}\end{array}$ & $2.53 \pm 0.63$ & $2.70 \pm 0.65$ & 0.004 & $2.24 \pm 0.44$ & $2.25 \pm 0.50$ & 0.950 \\
\hline $\begin{array}{l}\text { Hemog- } \\
\text { lo- } \\
\text { bin,gr/dL }\end{array}$ & $13.47 \pm 2.03$ & $13.75 \pm 2.04$ & 0.002 & $12.98 \pm 1.60$ & $12.65 \pm 1.81$ & 0.136 \\
\hline $\begin{array}{l}\text { Trombo- } \\
\text { sit, } / \mathrm{mm}^{3}\end{array}$ & $289.30 \pm 71.07$ & $290.74 \pm 75.37$ & 0.629 & $291.72 \pm 70.05$ & $291.54 \pm 55.42$ & 0.990 \\
\hline NLO & $1.84 \pm 1.01$ & $1.94 \pm 0.77$ & 0.008 & $2.56 \pm 1.03$ & $2.74 \pm 1.38$ & 0.390 \\
\hline TLO & $119.85 \pm 40.20$ & $112.78 \pm 33.83$ & 0.050 & $134.81 \pm 45.71$ & $136.53 \pm 43.33$ & 0.884 \\
\hline
\end{tabular}

TLO: Trombosit lenfosit oranı; NLO: Nötrofil lenfosit oranı;

TSH: Tirotropin/tiroid stimülan hormon 
Her iki gurupta da başlangıç biyokimyasal değerler ile tedavi sonrası biyokimyasal değerler değerlendirildiğinde TSH, sT3, sT4 düzeylerinde anlamlı $(p<0,005)$ bir artış vardı. Tüm hastalar birlikte değerlendirildiğinde tedavi öncesi NLO' da (1.96 $\pm 1.05^{\prime}$ den $2.08 \pm 0.95^{\prime}$ e) artış varken $(p=0.268)$, TLO' da (122.48 \pm 41.42 ' den $116.96 \pm 36.63^{\prime}$ e) azalma $(p=0.08)$ vardı ancak bu değişimler istatistiksel anlamlı değildi. GH grubunda tedavi öncesi nötrofil sayısı (4.36 $\pm 1.75^{\prime}$ den $5.01 \pm 1.72$ ' ye), lenfosit sayısı ( $2.53 \pm 0.63^{\prime}$ den $2.70 \pm 0.65$ ' ye) ve NLO(1.84 \pm 1.01 'den $1.94 \pm 0.77$ 'ye) anlamlı olarak artarken (sırasıyla $p=0.007, p=0.004$, $p=0.001)$, TLO değerlerinde ise anlamlı fark yoktu $(p=0.166)$ (Tablo-1). Tedavi öncesi GH grubunda TNG/MNG grubu ile kıyaslandığında nötrofil, lenfosit değerleri ve NLO anlamlı olarak düşüktü (Tablo 2).

Tablo 2. Tedavi öncesi nötrofil, lenfosit ve NLO değerleri

\begin{tabular}{llll}
\hline Tedavi öncesi & Graves Hastalığı & Nodüler / Multinodüler & $\mathrm{P}$ \\
\hline Lökosit & $7.807 \pm 1.92$ & $8.70 \pm 2.26$ & 0.096 \\
Nötrofil & $4.371 \pm 1.78$ & $5.563 \pm 2.08$ & $\mathbf{0 . 0 1 9}$ \\
Lenfosit & $2.545 \pm 0.63$ & $2.247 \pm 0.44$ & $\mathbf{0 . 0 1 2}$ \\
Trombosit & $289.2 \pm 70.81$ & $291.7 \pm 70.05$ & 0.881 \\
NLO & $1.84 \pm 1.01$ & $2.56 \pm 1.03$ & $\mathbf{0 . 0 0 6}$ \\
TLO & $119.85 \pm 40.20$ & $134.81 \pm 45.71$ & 0.166 \\
\hline
\end{tabular}

TLO: Trombosit lenfosit oranı; NLO: Nötrofil lenfosit oranı;

\section{Tartışma}

$\mathrm{GH}$, hipertiroidizmin en yaygın nedeni ve tiroidin doku spesifik anormal B ve T lenfositlerce infiltrasyonu ile karakterize otoimmün endokrin bir hastalıktır(18). Tiroid hormonları insanlarda önemli fizyolojik öneme sahiptir.Tiroid hastalıkları ile hematolojik anormallikler arasındaki ilişki iyi bilinmektedir(19). Lökositler ve alt grupları olan nötrofiller ile lenfositler enflamasyon ve immün yanitta rol oynar(14). Trombositler patogenezde etkilidirler. Trombositler ve lenfositler birbirlerinin işlevi artııırlar(20). Antitiroid ilaçların tiroid hormon düzeyleri ile birlikte antiinflamatuvar etkileri de vardır. Nötropeni ise anti-tiroid ilaçların bilinen en ciddi komplikasyonudur(21). GH' nın anti-tiroid ilaçlar ile tedavisi, hastaların çoğunda otoimmünitenin zamanla remisyonu ile birliktedir. Bu remisyonun arkasındaki en olası mekanizmanın, ilaçlarııın doğrudan immünosüpresif etkisi olduğu düşünülmektedir(22). Son çalışmalarda, çeşitli biyomarkerlerin, özellikle NLO ve TLO' nın inflamatuar yanıtla ilişkili olduğunu gösterilmiştir(9,23-26). NLO' nın tiroid hastalıkları ve diğer hastalıklarda inflamatuar bir belirteç olarak kullanılabileceğini öne süren çalışmalar da mevcuttur. Ve bu çalışmalarda $\mathrm{GH}$ olanlar ve sağ lıkı kontroller arasındaki fark değerlendirilmiştir(27-31). Biz ise çalışmamızda GH ve TNG/MNG gruplarını karşılaş̧ırdık. Otoimmün bir hastalık olan GH grubunda kendi içinde NLO düzeylerinde anlamlı artış saptadık. Tedavi öncesi iki grup karşılaştııılığında da
GH ile TNG/MNG arasında anlamlı fark mevcuttu.

Peng Y. ve ark. ise tedavi edilmemiş GH ile karşılaş̧ıııldığında tedavi ile ötiroid olan hastalarda nötrofil düzeylerinin artmış olduğunu raporladılar. Bu çalışmada nötrofil düzeyleri artmıştı ancak bu artış istatistiksel anlamlı değildi (32). Biz de Peng ve arkadaşlarının çalışmasına benzer şekilde tedavi sonrası öncesine göre nötrofil düzeylerinde artış saptadık ancak bizim çalışmamızdaki bu artış istatistiksel anlamlıydı. Klatka ve arkadaşları ise antitiroid tedavi ile lenfosit düzeylerinin hafifçe azaldığını bildirmiş̧ir. Bu bulguların ilaçların anti-inflamatuvar etkisi ile ilişsili olabileceği ve ilaçların patolojik inflamasyonu azaltabileceğini savunmuşlardır (33). Çalışmamızda ise antitiroid tedavi sonrası lenfosit düzeylerinde de artış vardı ki yine bu artış da istatistiksel anlamlıydı. Bir diğer çalışmada NLO' nın GH olan hastalarda antitiroid ilaç sonrası nüksü öngörmek için erken bir prognostik biyobelirteç olabileceği öngörülmüştür (34). Bununla birlikte, artmış NLO ve GH hastalarının kötü prognozu arasındaki etkileşime dahil olan spesifik mekanizmalar net değildir. GH bir otoimmün tiroid bozukluğu olduğundan, patogenezinde çeşitli bağışıklık mekanizmaları yer alabilir. Gravesli hastalarda hematolojik değişiklikler, aşırı tiroid hormonlarından ziyade immünolojik nedenli$\operatorname{dir}(4,35)$.

Seksenaltı GH ve 112 kontrol kohortunun olduğu bir çaIışmada NLO tedavi edilmemiş GH hastalarında kontrol grubuna göre önemli ölçüde düşük, TLO ise iki grup arasında benzer saptanmış(27). Biz de çalışmamızda tedavi öncesi GH grubunda NLO'yu TNG/MNG grubuna göre anlamlı düşük saptadık. Anti-tiroid ilaçların inflamasyon üzerine etkisi GH grubunda olmuştur ancak TNG/MNG grubunda olmamıştır. NLO basit ve kolay ölçülebilir bir tetkiktir, inflamasyonu göstermede çelişkili sonuçlar çıkabilmektedir. Bizde NLO' nda artış gözlenmiş olup bu durumun çaışmadaki hasta sayısı azlığı ve çalışmanın retrospektif planlanmış olması gibi birkaç eksiklikten kaynaklanabileceğini düşündük. Bunun yanında GH'nda tedaviyi en az 11.5 yıl devam ettirmek gerektiğinden ve bizim erken dönemde ( 3 ve 6 . ay) bakmış olmamızdan belki de hastalık remisyona girmeden yapılan tetkiklerin değerlendirilmesi sonuçları etkilemiş olabilir. Daha uzun süreli, daha çok hasta sayısı olan prospektif çalışmalara intiyaç olduğu aşikardır. Hipertiroidizme bağı kemik iliğinde bir seride supresyon ve buna bağlı anormallikler sık bildirilmektedir. Hipertiroidizmli hastalarda kemik iliğindeki supresyonun mekanizması net olmamakla birlikte, kısmen otoimmün mekanizma ve/ veya pluripotent kök hücrelerin olgunlaşması ve farklılaşması bozuklukları nedeniyle tam kan bileşenlerinin ömrünün kısalması ile ilişkili olabilir. Kemik iliğindeki supresyonun hipertiroidizmin ötiroid hale gelmesi ile düzelmesi, iki durum arasındaki geçici ilişkiyi göstermektedir (36). Yaptığımız bu çalışmada tedavi öncesi GH grubunda nötrofil, lenfosit,trombosit,hemoglobin ve NLO' nı düşük saptamış olmamızın nedeni kemik iliğindeki supresyon 
olabilir. Ve tedavi sonrası nötrofil, lenfosit, trombosit, hemoglobin ve NLO' nında artış gözlenmesi anti-tiroid ilaç verilmesi ile supresyonun azalması olarak açıklanabilir ve bu da NLO'nın GH' da kullanılamayacağını göstermektedir.

\section{Etik Onam: Çalışma için Harran Üniversitesi Tıp Fakültesi Etik Kurulu'ndan etik onam alındı (05.11.2018/11/14)}

\section{Kaynaklar}

1. Kravets I. Hyperthyroidism: Diagnosis and Treatment. Am Fam Physician. 2016;93(5):363-70.

2. Kim WG, Kim WB, Woo G, Kim H, Cho Y, Kim TY, et al. Thyroid stimulating hormone reference range and prevalence of thyroid dysfunction in the Korean population: Korea National Health and Nutrition Examination Survey. Endocrinol Metab. 2017;32(1), 106-114.

3. De Leo S, Lee SY, Braverman LE. Hyperthyroidism. Lancet. 2016Aug27;388(10047):906-918

4. Ross DS, Burch HB, Cooper DS, Greenlee MC, Laurberg P, Maia AL, et al. American Thyroid Association Guidelines for Diagnosis and Management of Hyperthyroidism and Other Causes of Thyrotoxicosis. Thyroid. 2016;26(10):1343-1421.

5. Wémeau JL, Klein M, Sadoul JL, Briet C, Vélayoudom-Céphise FL. Graves' disease: Introduction, epidemiology, endogenous and environment alpathogenic factors. Ann. Endocrinol. 2018 Dec;79(6):599-607.

6. Azab B, Bhatt VR, Phookan J, Murukutla S, Kohn N, Terjanian T, et al. Usefulness of the neutrophil-to-lymphocyte ratio in predicting shortand long-term mortality in breast cancer patients. AnnSurgOncol. 2012;19:217-24.

7. Kishi Y, Kopetz S, Chun YS, Palavecino M, Abdalla EK, Vauthey JN Blood neutrophil-to-lymphocyte ratio predicts survival in patients with colorectal liver metastases treated with systemic chemotherapy. AnnSurgOncol 2009;16:614-22.

8. Wang S, Zhang Z, Fang F, Gao X, Sun W, Liu H. The neutrophil/lymphocyte ratio is an independent prognostic indicator in patients with bone metastasis. OncolLett. 2011;2:735-40.

9. Seretis C, Gourgiotis S, Gemenetzis G, Seretis F, Lagoudianakis E, Dimitrakopoulos $\mathrm{G}$. The significance of neutrophil/lymphocyte ratioas a possible marker of underlying papillary microcarcinomas in thyroidal goiters: a pilot study. Am J Surg. 2013;205:691-6.

10. Zhu Y, Si W, Sun Q, Qin B, Zhao W, Yang J. Platelet-lymphocyte ratio acts as an indicator of poor prognosis in patients with breast cancer. Oncotarget. 2017;8(1):1023-30.

11. Prodromidou A, Andreakos $P$, Kazakos $C$, Vlachos DE, Perrea D, Pergialiotis $\mathrm{V}$. The diagnostic efficacy of platelet-to-lymphocyte ratio and neutrophil-to-lymphocyte ratio in ovarian cancer. InflammRes. 2017;66(6):467-75.

12. Idil Soylu A, Arikan Cortcu S, Uzunkaya F, Atalay YO, Bekci T, Gungor $\mathrm{L}$, ve ark. The correlation of the platelet-to-lymphocyte ratio with the severity of stenosis and stroke in patients with carotid arterial disease. Vascular. 2017;25(3):299-306.

13. Zhang M, Huang XZ, Song YX, Gao P, Sun JX, Wang ZN. High platelet-to-lymphocyte ratio predicts poor prognosis and clinicopathological characteristics in patients with breast cancer: a meta-analysis. BiomedResInt. 2017:9503025.

14. Imtiaz F, Shafique K, Mirza SS, Ayoob Z, Vart P, Rao S. Neutrophil lymphocyte ratio as a measure of systemic inflammation in prevalent chronic diseases in Asian population. Int. Arch. Med 2012; 5(1):2.

15. Buyukkaya E, Karakas MF, Karakas E, Akçay AB, Tanboga IH, Kurt $M$ ve ark. Correlation of neutrophil to lymphocyte ratio with the presence and severity of metabolic syndrome. ClinApplThrombHemost. 2014;20:159-63.

16. Hamminga EA, van der Lely AJ, Neumann HA, Thio HB: Chronic inflammation in psoriasis and obesity: implications for therapy. MedHypotheses 2006;67:768-73.
17. Turkmen K, Erdur FM, Ozcicek F, Ozcicek A, Akbas EM, Ozbicer A ve ark. Platelet-to-lymphocyte ratio beter predicts inflammation than neutrophil-to-lymphocyte ratio in end-stage renal disease patients. Hemodiallnt 2013;17:391-6.

18. Pozzilli $P$, Carotenuto $P$, Delitala G. Lymphocyti traffic and homing into target tissue and the generation of endocrine autoimmunity. Clinicalendocrinology. 1994; 41:545-554.

19. Bagir GS, Haydardedeoglu, FE, Bakiner, OS, Bozkirli E, Ertorer ME. Mean Platelet Volume in Graves' disease: A Sign of Hypermetabolism Rather than Autoimmunity?. Pak. J. Med. 2017;33(4):871-875.

20. Li N. Platelet-lymphocyte cross-talk. J LeukocytBiol 2008; 83(5): 1069-1078.

21. Turan E, Kaya A, Kulaksızoğlu M, Kandemir B, Erayman İ. Neutropenia Due to Very Long Time Propylthiouracil Usage in Toxic Multinodular Goiter. Turk J EndocrinolMetab 2016;20:16-18.

22. Laurberg P. Remission of Graves' disease during anti-thyroid drug therapy. Time to reconsider the mechanism? Eur J Endocrinol. 2006 Dec;155(6):783-6.

23. Roxburgh CS, McMillan DC. Role of systemic inflammatory response in predicting survival in patients with primary operable cancer. FutureOncol. 2010; 6(1):149-163.

24. Bayir O, Karagoz T, Ocal B, Cakal E, Saylam G, Korkmaz MH. Predictive role of neutrophil-lymphocyte and platelet-lymphocyte ratios in thyroid nodules with cytological diagnosis of "undetermined significance" and "suspicious for malignancy". ENT Updates 2017;7(1):28-32. 25. Kim SM, Kim EH, Kim BH, Kim JH, Park SB, Nam YJ, et al. Association of the Preoperative Neutrophil-to-ymphocyte Count Ratio and Platelet-to-Lymphocyte Count Ratio with Clinicopathological Characteristics in Patients with Papillary Thyroid Cancer. Endocrinol. Metab. (Seoul), 2015;30(4):494-501.

26. Han S.W.,Kang S.Y., Kim S.K.,Youn H.J.,Jung S.H. Clinical significance of blood neutrophil-to-lymphocyte ratio in patients with papillary thyroid carcinoma. Korean J. Endocr. Surg. 2014;14:184-189.

27. Turan $E$. Evaluation of neutrophil-to-lymphocyte ratio and hematologic parameters in patients with Graves' disease. Bratisl. Lekarskelisty. 2019;120(6):476-480.

28. Dağdeviren M, Akkan T, Yapar D, Karakaya S, Dağdeviren T, Ertuğrul $D$, ve ark. Can neutrophil/lymphocyte ratio be used as an indicator of inflammation in patients with hyperthyroidism?. J Med Biochem. 2019; 38:1-6.

29. Eakin DL, Peake RL, Weiss GB. Effect of therapy on theneutropenia of hyperthyroidism. South. Med. J. 1983;76(3):335-337, 340.

30. Aggarwal N, Tee SA, Saqib W, Fretwell T, Summerfield GP, Razvi S. Treatment of hyperthyroidism with antithyroid drugs corrects mild neutropenia in Graves' disease. Clin. Endocrinol. 2016;85(6);949-953.

31. Van der Weerd K, Van Hagen PM, Schrijver B, Kwekkeboom DJ, De Herder, WW, Ten Broek MR. et al. The peripheral blood compartment in patients with Graves' disease: activated T lymphocytes and increased transitional and pre-naive mature B lymphocytes. Clin. Exp. Immunol. 2013;174(2):256-264.

32. Peng Y, Qi Y, Huang F, Chen X, Zhou Y, Ye L, et al. Down-regulated resistin level in consequence of decreased neutrophi counts in untreated Grave'sdisease. Onco target 2016;7(48):78680-78687.

33. Klatka M, Grywalska E, Surdacka A, Tarach J, Klatka J, Rolinski J. Peripheral blood lymphocyte apoptosis and its relationship with thyroid function tests in adolescents with hyperthyroidism due to Graves' disease. ArchMedSci 2012;8(5):865-873.

34. Kim M, Kim BH, Jang MH, Kim JM, Kim EH, Jeon YK, et al. High neutrophil-to-lymphocyte ratio is associated with relapse in Graves' disease after antithyroid drug therapy. Endocrine. 2020 Feb;67(2):406411.

35. Ford HC, Carter JM. The haematology of hyperthyroidism: abnormalities of erythrocytes, leucocytes, thrombocytes and haemostasis. Postgrad. Med. J. 1988; 64(756):735-742.

36. Hegazi M, Kumar R, Bitar Z, Ibrahim E. Pancytopenia related to Graves' disease. AnnSaudiMed 2008;28:48-9. 